\title{
The Practical Source of Educational Knowledge for Pre-Service Teachers in Confronting Field-Based Challenges in School Practicum
}

\author{
Hsien-Chang Tsai ${ }^{1} \&$ Shih-Hsiung Liu ${ }^{2}$ \\ ${ }^{1}$ Department of Biology, National Changhua University of Education, Taiwan \\ ${ }^{2}$ Center for Teacher Education, National Changhua University of Education, Taiwan \\ Correspondence: Shih-Hsiung Liu, Center for Teacher Education, National Changhua University of Education, \\ No.1 Jin-De Road, Changhua city 500, Taiwan. Tel: 886-4-7232105. E-mail: shsiung@cc.ncue.edu.tw
}

\author{
Received: May 24, 2013 Accepted: June 22, 2013 Online Published: July 18, 2013 \\ doi:10.5539/hes.v3n4p67 URL: http://dx.doi.org/10.5539/hes.v3n4p67
}

\begin{abstract}
Educational value in teacher education courses is unquestioned; however, there are still many doubts about the practicality of the knowledge acquired from university courses and a field-based course in school practicum. The purpose of this study is to identify the practicality of the educational knowledge from the above courses for pre-service teachers in confronting field-based challenges in school practicum. A survey method was utilized to collect the data about pre-service teachers' perceptions on the acquisition of educational knowledge as well as practicality of the knowledge. A total of 298 Taiwanese pre-service teachers were invited to fill in a validated questionnaire in January 2013, which is the last month in school practicum. Data were analyzed using the Friedman test and multiple regression analysis. This study concludes that disciplinary content knowledge was perceived as the top-ranked one among six categories of educational knowledge from university courses, while this category of knowledge was perceived as the fourth-highest order on practicality of the knowledge. The finding implies that university courses do not fit to the needs of pre-service teachers in confronting challenges in school practicum. Except for disciplinary content knowledge, other categories of educational knowledge tended to maintain approximate rank-order. Another finding reveals that all categories of educational knowledge from the field-based course were significant predictors of practicality of the educational knowledge, while all those acquired from university courses were not. A recommendation was proposed that teacher educators in universities should build a course version of practical knowledge through integrating field-based experiences into teacher education courses.
\end{abstract}

Keywords: educational knowledge, pre-service teachers, field-based course, teacher education program

\section{Instruction}

Pre-service teachers are required to complete teacher education program, consisting of university courses and a field-based course, before certificated. The teacher education courses in university provide the theoretical foundations for educational practice, while the field-based course implemented in school practicum is considered as a situated learning environment where pre-service teachers can sense educational practice embedded in the classroom and school contexts. A field-based course is not equal to school practicum. During a half-year field-based course, a professor in teacher education institute often collaborates with school teachers to design a series of training activities as well as to provide relative knowledge to a pre-service teacher. However, the school practicum, in addition to the above mentioned, refers to a field experience that involves a pre-service teacher's treatments of facing various people, affairs and equipments. A question is whether the educational knowledge acquired regardless of from university courses and from a field-based course fits with the needs of a pre-service teacher in confronting various problems during practicum. That is, even though educational value of teacher education program is unquestioned, there are still many doubts about practicality of the educational knowledge acquired from the above two categories of courses for pre-service teachers in confronting field-based challenges in school practicum.

Feiman-Nemser (1990) distinguished between an academic orientation and a practical orientation, exemplifying the goal of teacher preparation, and stated that within academic orientation, the emphasis is on mastery of both the subject matter and subject-matter pedagogy. Within practical orientation, the knowledge for teaching is understood as a mix between craft and technique through an experience-based apprenticeship model. A 
conceptualization of the theory-practice relationship, connecting university courses and a field-based work, reveals a possibility of the integration of theory courses and practice experiences. Montecinos, et al. (2011) argued that this theory-practice relationship allows pre-service teachers to employ the skills and knowledge developed at previous courses as well as to reflect on their actions through theoretical frameworks that can be interrogated and refined. Nevertheless, few teacher education courses in a university are involved in strengthening the theory-practice relationship. In Taiwan, the processes of a pre-service teacher becoming a school teacher at least include two phases, enrolling in university courses and participating in a half-year field-based course, and two of examinations, one for certification and, if pass, another one for being employed by a school. The former two phases mainly equip a pre-service teacher with competences to be a teacher in the future. However, the two categories of courses do not simply guarantee whether the knowledge acquired by pre-service teachers fits with educational practice. In brief, what knowledge pre-service teachers learn in university courses and what knowledge they acquire in a field-based course do not necessarily satisfy the needs of those who overcome the challenge in school practicum.

Generally, educational knowledge in teacher education courses includes theoretical/propositional knowledge and practical knowledge. Eraut (1994) classified educational knowledge into three categories: (a). discipline-based theories and concepts, derived from bodies of coherent, systemic knowledge, (b). generalizations and practical principles in the applied field of professional action, and (c). specific principles about particular cases, decisions and actions.

In Taiwan, teacher education courses that are regulated by the Ministry of Education consist of three core sections, discipline courses, pedagogy courses and a field-based course (Ministry of Education, 2011). The three categories of courses distribute professional knowledge in a teacher education program. Based on a curriculum framework regulated by Taiwanese Ministry of Education, pedagogy courses consist of "education foundation courses" (e.g., philosophy of education, educational psychology), "education method courses" (e.g., principles of instruction, classroom management), "subject area curriculum and methodology" (e.g., teaching material and method of mathematics) and "elective courses" for pre-service teachers interested in exploring in teacher career (e.g., school administration, interpersonal relationship and communication). The pedagogy courses are considered as an ideal that meets a teachers' professional standard (Ministry of Education, 2013). Moreover, the discipline courses and pedagogy courses are arranged as academic credits of teacher education by universities, while the field-based course in school practicum is designed as multiple aspects of training activities, consisting of teaching practice, classroom management practice, administrative practice, and participating in professional development activities according to the regulations from Ministry of Education. A pre-service teacher enrolling in field-based course is jointly supervised by a university professor and school teachers. Pre-service teachers are arranged to have a meeting in fixed time with their professors and mentors, respectively. At that time, they would acquire skills and knowledge related to educational practice.

Moreover, Celik (2011) reviewed literature and proposed that teachers' expertise relates to subject matter knowledge, knowing how to teach the subject matter to others (didactical knowledge), knowledge about how students learn, feel and develop (pedagogical knowledge), and self-reflection and social skills. Except for subject matter knowledge and pedagogical knowledge, the majority of universities with a teacher education institute in Taiwan also provide educational material to equip pre-service teacher with self-reflection and social skills in relative courses. However, the contents of the courses are often narrowed to classroom discussion activities.

Cochran-Smith and Lytle (1999) argued that a field-based course could provide pre-service teachers with the opportunities to self-reflect by discussing with their mentors on various educational practices. According to LaBoskey (2010), reflection is the means by which human beings learn from their experiences so as to improve themselves and their society. In terms of pre-service teachers, reflection is a means to learn from practice, which can subsequently be employed to improve that practice. By acquiring the knowledge of self-reflection from mentors during the field-based course, pre-service teachers are able to promote their professional knowledge. Moreover, Maynard (2007) also proposed that a field-based course offers pre-service teachers opportunities of self-reflections for the purpose of professional growth. The category of educational knowledge was acquired by pre-service teachers from a field-based course more than from university courses.

As for social skills, a study by Montecinos, et al. (2011) suggested that pre-service teachers were mostly interested in learning about what teachers and students do in the classroom; however, in order to obtain a sufficient opportunity of classroom observation, a prerequisite was to learn how to develop positive interpersonal relationships with students and school personnel. Evelein, Korthagen, and Brekelmans' (2008) highlighted that pre-service teachers desire to fulfill psychological needs of positive interpersonal relationships when they work in the schools. In a field-based course, mentors in schools might guide pre-service teachers about how to build 
positive relationships with students, colleagues, and parents. Interpersonal relationship knowledge in a field-based course may be perceived more than university courses.

Furthermore, Tseng, Hou, Hsu and Chen (2006) argued that pedagogical knowledge includes teaching materials, teaching methods, administrative knowledge, and counseling knowledge and classroom management. Of which, administrative knowledge is appeared on Taiwanese academic literature more than on international journal. In Taiwan, administrative practice is a part of the field-based course that is regulated by a government regulation related to school practicum. Pre-service teachers are asked to learn and participate in administrative works (e.g., holding student contests and holding parents' day) by their mentors' guidance, in which they can understand administrative affairs through learning by doing in a school. There is also an academic course in university to provide pre-service teachers with knowledge on administrative works. Theoretically, the administrative knowledge acquired from a field-based course is more practical than the knowledge from university courses.

As for consultation knowledge previously mentioned, similar to Tseng et al. (2006), Baumert and Kunter (2013) distinguished counseling knowledge from general pedagogical knowledge and defined it as what professionals need in order to communicate effectively with laypeople. Baumert and Kunter stated that counseling knowledge is largely non-subject-specific form of knowledge that has to be bundled and interpreted for specific addressees in a given counseling situation. In the school context, common reasons for counseling include upcoming decisions at critical points in students' educational careers, learning difficulties, and behavioral problems (cited from Baumert and Kunter, 2013). Moreover, Tseng et al. and Baumert et al. also distinguished classroom management knowledge from general pedagogical knowledge and identified that classroom management is an important knowledge. In Taiwan, classroom management practice is a part of assessment of the field-based course. There is also an academic course in university to equip pre-service teachers with competences on classroom management. Because a few of common knowledge exists between counseling knowledge and classroom management knowledge, such as dealing with students' conflicts, classroom management knowledge is involved in consultation knowledge in the study. In terms of knowledge acquirement, university courses only provide pre-service teachers with subject-specific form of counseling knowledge, while a field-based course gives pre-service teachers opportunities to learn the methods of counseling students under mentor's guidance.

By summarizing the above literature and previously describing the curriculum framework in Taiwanese teacher education, this study demonstrates that educational knowledge consists of disciplinary content knowledge, pedagogical knowledge, self-reflection knowledge, interpersonal relationship knowledge, school administrative knowledge, and consultation knowledge.

Moreover, a study by Joram (2007) suggested that the majority of pre-service teachers expressed the importance of specific skills of teaching they should learn in a field-based course. Pre-service teachers might not value university courses as much as their field-based course because the field-based course is on a mission to acquire very specific professional skills of teaching in practice schools. A focus on the "how to" of teaching perceived by pre-service teachers, according to Joram, reveals that university-based instruction is less valued than the field-based course.

Ideally, a university with teacher education institute designs teacher education courses to equip pre-service teachers with a variety of educational knowledge. A field-based course provides pre-service teachers with educational knowledge through a university professor collaborating with school teachers. However, as mentioned, the above two categories of courses do not simply guarantee whether the knowledge acquired by pre-service teachers satisfies the needs of confronting the challenges in their school practicum

Murray (2010) also claimed that even though teacher educators succeed and the pre-service teachers learn the content of the teacher education curriculum, there is still no guarantee that the teacher based his or her teaching practice on some knowledge of education acquired in the teacher education program. That is, when pre-service teachers confront the challenges in their school practicum, which source of educational knowledge acquired by pre-service teachers can provide them with sufficient knowledge to deal with those challenges?

A study by Deed, Cox and Prain (2011) suggested that pre-service teachers identified theory in the core subjects as both the most and least useful aspects of the course in teacher education programs. Cheng, Tang and Cheng (2012) explored integration of theoretical knowledge learnt in the university to practice in different school contexts and indicated that teacher educators in university play a predominantly important role in facilitating the development of attitudes and skills for reflection. The above demonstrations indicated that teacher education courses in university should not overly be theorized but be formed in an integrated curriculum system with a common core between university courses and a field-based course. Nevertheless, university courses might not achieve the desired goal. In contrast, the field-based course provides pre-service teachers an opportunity to refine 
and reflect on educational practice. Moreover, the experiences of pre-service teachers in school practicum are very powerful in shaping a teacher's views of education because they are perceived as being 'real' as opposed to the 'artificial' environment of the theorizing courses (Grootenboer, 2005/2006), especially when pre-service teachers face, and even, resolve unexpected problems in school practicum. However, whether university courses and a field-based course can offer pre-service teachers with sufficient knowledge to face, and even, resolve unexpected problems may be questioned. Few studies have explored the practicality of educational knowledge from university courses and from a field-based course, especially when pre-service teachers confront the challenges in their school practicum. Based on the above demonstrations, two research questions are addressed.

1) In terms of six categories of educational knowledge, how do the pre-service teachers rank their educational knowledge acquisition from university courses and from a field-based course, respectively, as well as practicality of the knowledge in confronting challenges in school practicum?

2) Which source of educational knowledge acquired by pre-service teachers can predict the practicality of the knowledge in confronting challenges in school practicum?

\section{Method}

A survey method was utilized to investigate the acquisition of educational knowledge and practicality of the knowledge perceived by pre-service teachers. In a university in Taiwan, 298 pre-service teachers who were enrolling in a field-based course were invited to fill in a validated questionnaire in January 2013, which is the last month in the field-based course.

The questionnaires, dividing into six categories of educational knowledge based on literature review, were employed to collect data about acquisition of educational knowledge and practicality of the knowledge perceived by pre-service teachers. Five experts were invited to review and to comment the initial 18 items in the questionnaires. Given comments and suggestions, there are twelve items in six categories of educational knowledge, acquired from university courses and from a field-based course respectively. Items asked pre-service teacher to response, ranging from 1 for "very little" to 5 for "very much". Another six items were designed to response the practicality of the knowledge in confronting challenges in school practicum, ranging from 1 for "very impractical" to 5 for "very practical".

The reliability of scales was analyzed. Cronbach's alpha coefficients were 0.810 for "educational knowledge acquisition from university courses," 0.787 for "educational knowledge acquisition from the field-based course," 0.701 for "practicality of knowledge in confronting field-based challenges" and 0.884 for the total scale.

Data were analyzed using the Friedman test and multiple regression analysis. Firstly, the Friedman test was employed to rank six categories of educational knowledge, acquired from the university courses and the field-based course, respectively. In addition, six categories of practicality of the knowledge in confronting challenges in school practicum were also ranked in the Friedman test. Secondly, multiple regression analysis was utilized to determine, in each category of educational knowledge, which source of educational knowledge acquired were significant predictors of practicality of the knowledge in confronting challenges in school practicum.

\section{Results and discussion}

\subsection{Rank-Order on Acquisition of Educational Knowledge and Practicality of the Knowledge}

The statistical results in Table 1 indicate that disciplinary content knowledge was the top-ranked one among six categories of educational knowledge perceived by pre-service teachers in university courses. However, disciplinary content knowledge was perceived as the fifth-highest order in the field-based course as well as was perceived as the fourth-highest order on practicality of the knowledge in confronting challenges in school practicum. That is, the disciplinary content knowledge was perceived as a high acquisition in university courses by pre-service teachers, while the knowledge was perceived as a low acquisition in the field-based course and as a low practicality. Similar to a study by Deed, et al. (2011) who indicated that theory in the core subjects was both the most and least useful aspects of the course in education programs, the above result imply that university courses in teacher education program do not fit to the needs of pre-service teachers in confronting the challenges in their school practicum.

Except for disciplinary content knowledge, other categories of educational knowledge tended to maintain approximate rank-order.

In terms of pedagogical knowledge, the analytic result reveals that the category of educational knowledge was perceived as the top-ranked one in the university courses and as the second-highest order in the field-based 
course. The category of educational knowledge was also considered as a practical knowledge in confronting challenges in school practicum, being ranked into the third-highest order category. Contrasting to a study by Joram (2007), suggesting that majority of pre-service teachers expressed the importance of specific skills of teaching, this study finding could demonstrate that specific skills of teaching are the notable knowledge among all categories of educational knowledge as well as the practically of the knowledge.

Table 1. Mean ranks of six categories of knowledge perceived by pre-service teachers

\begin{tabular}{lccc}
\hline \multirow{2}{*}{$\begin{array}{l}\text { Types of perceived knowledge } \\
\text { Self-reflection knowledge }\end{array}$} & $\begin{array}{l}\text { from the } \\
\text { university courses } \\
\text { (mean ranks) }\end{array}$ & $\begin{array}{l}\text { from the } \\
\text { (mean ranks) }\end{array}$ & $\begin{array}{c}\text { on practicality } \\
\text { (mean ranks) }\end{array}$ \\
\cline { 2 - 4 } Interpersonal relationship knowledge & $\chi^{2}=351.064^{*}$ & $\chi^{2}=28.235{ }^{*}$ & $\chi^{2}=274.394^{*}$ \\
Pedagogical knowledge & $4(4.05)$ & $2(3.64)$ & $1(3.85)$ \\
Disciplinary content knowledge & $2(4.11)$ & $3(3.61)$ & $2(3.79)$ \\
Consultation knowledge (including classroom management) & $5(3.07)$ & $1(3.76)$ & $3(3.78)$ \\
School administrative knowledge & $6(2.20)$ & $4(3.35)$ & $5(3.54)$ \\
\hline
\end{tabular}

${ }^{*} p<.01, d f=5, N=281$

In addition, Table 1 also shows that consultation knowledge and school administrative knowledge tend to be ranked as low order in six categories of educational knowledge. In Taiwanese teacher education program, participating in consulting activities (including classroom management) and school administrative affairs are a part of assessment of the field-based course for pre-service teachers. However, pre-service teachers just assist school teachers in dealing with affairs rather than being charged with responsibility. The above situation might result in a neglect of equipping pre-service teachers with the competences. This explains why the two categories of educational knowledge was neither perceived sufficient acquisition regardless of from university courses and from the field-based course, nor perceived as a practical knowledge.

Notably, self-reflection knowledge and interpersonal relationship knowledge are the top two categories on practicality of the knowledge. By comparing to the educational knowledge from the university courses and the field-based course, the two categories of knowledge on practicality just slightly differ in rank-order. However, as mentioned by Cochran-Smith and Lytle (1999), learning on the competences of self-reflection benefits the development of professional knowledge. This study finding demonstrates that self-reflection knowledge has been considered as a practical knowledge by pre-service teachers in confronting challenges in school practicum. In addition, positive interpersonal relationships with students and school personnel satisfy pre-service teachers' psychological needs and benefit them on learning educational knowledge, according to Evelein, et al. (2008) and Montecinos, et al. (2011). In this study, interpersonal relationship knowledge is the second-highest order on practicality of the knowledge. In Taiwan, teacher education courses in university mainly provide pre-service teachers with disciplinary content knowledge and skills of teaching because pre-service teachers need to pass an examination to gain teacher certificate, and to demonstrate their teaching skills for being employed by a school. Thus, few courses in university focus on interpersonal relationship knowledge. The above perspectives explain why interpersonal relationship knowledge were ranked into the second-highest order on practicality of the knowledge, while were ranked into the fourth-highest order on the knowledge acquisition from university courses by pre-service teachers.

\subsection{Predictors of Practical Source of Educational Knowledge in Confronting Challenges in School Practicum}

A field-based course provides pre-service teachers with skills and knowledge to experience educational practice. During enrolling in the field-based course, pre-service teachers have also begun confronting the challenges related to educational practices in their school practicum. How to deal with unfamiliar matter depends on pre-service teachers' competences that are equipped with university courses and a field-based course. Notably, Table 2 reveals that all categories of educational knowledge from the field-based course were significant predictors of practicality of the educational knowledge, while those categories of knowledge from university courses were not. Specifically, the six categories of educational knowledge acquired from the field-based course 
significantly fit to the practicality of the educational knowledge in confronting challenges for pre-service teachers in school practicum.

Table 2. Summary of results of multiple regression analysis for practicability of educational knowledge

\begin{tabular}{|c|c|c|c|c|c|}
\hline $\begin{array}{l}\text { Dependent variables } \\
\text { (knowledge practicability) }\end{array}$ & $\begin{array}{l}\text { Independent variables } \\
\text { (knowledge from the courses) }\end{array}$ & $F$ & $\beta$ & $p$ & $R^{2}$ \\
\hline \multirow{2}{*}{$\begin{array}{l}\text { School administrative } \\
\text { knowledge }\end{array}$} & from the university courses & \multirow{2}{*}{$16.078^{*}$} & .076 & .200 & \multirow{2}{*}{.097} \\
\hline & from the field-based course & & .291 & .000 & \\
\hline \multirow{2}{*}{$\begin{array}{l}\text { Interpersonal } \\
\text { knowledge }\end{array}$} & from the university courses & \multirow{2}{*}{$9.834^{*}$} & -.057 & .414 & \multirow{2}{*}{.059} \\
\hline & from the field-based course & & .283 & .000 & \\
\hline \multirow{2}{*}{ Self-reflection knowledge } & from the university courses & \multirow{2}{*}{$4.445^{*}$} & .045 & .514 & \multirow{2}{*}{.024} \\
\hline & from the field-based course & & .148 & .032 & \\
\hline \multirow{2}{*}{ Disciplinary content knowledge } & from the university courses & \multirow{2}{*}{$4.098^{*}$} & .016 & .794 & \multirow{2}{*}{.022} \\
\hline & from the field-based course & & .163 & .009 & \\
\hline \multirow{2}{*}{ Consultation knowledge } & from the university courses & \multirow{2}{*}{$3.532^{*}$} & -.016 & .796 & \multirow{2}{*}{.018} \\
\hline & from the field-based course & & .161 & .010 & \\
\hline \multirow{2}{*}{ Pedagogical knowledge } & from the university courses & \multirow{2}{*}{$2.468^{*}$} & .011 & .859 & \multirow{2}{*}{.010} \\
\hline & from the field-based course & & .128 & .046 & \\
\hline
\end{tabular}

In terms of school administrative knowledge, since participating in school administrative affairs is a part of assessment of a field-based course, pre-service teachers learn a few of administrative skills with mentors' guidance by doing. It is reasonable that school administrative knowledge acquired from the field-based course predicted practicality of the knowledge in confronting challenges in school practicum. As discussed in the previous literature, the administrative knowledge acquired from a field-based course is more practical than the knowledge from university courses.

As mentioned, interpersonal relationship knowledge and self-reflection knowledge were the top two practicality of the knowledge. During enrolling in a field-based course, pre-service teachers need to interact with personnel for educational practices. At that time, the field-based course can provide them with the opportunities to contact their mentors for advices. In addition, as Cochran-Smith and Lytle (1999) mentioned, a field-based course provides pre-service teachers with the opportunities to self-reflect by discussing with their mentors on various educational practices. In contrast, the knowledge acquired from university courses might hardly equip pre-service teachers with sufficient competences due to lack of experiences on educational practice. This is why interpersonal relationship knowledge and self-reflection knowledge acquired from the field-based course could predict the practicality of the category of educational knowledge,

Notably, disciplinary content knowledge acquired from the field-based course rather than that from the university courses significantly predicts the practicality of the category of educational knowledge. As previous finding in this study, disciplinary content knowledge from university courses perceived by pre-service teachers was the top-ranked one in all educational knowledge. Contrasting to the above two results, the study demonstrates that disciplinary content knowledge from university courses might be overly theorizing, not fitting with the needs of pre-service-teachers in confronting the challenges in their school practicum, as previously discussed.

Consultation knowledge, including classroom management, is a part of assessment of the field-based course. In Taiwan, pre-service teachers who are enrolling in a field-based course are arranged into a classroom, in which they learn how to manage a classroom and how to interact with students. Even though university courses provide some concepts and skills of consultation, the mentor of each pre-service teacher can directly advise the way of dealing with classroom affairs. Thus, consultation knowledge from the field-based course is superior to that from university courses on practicality of the educational knowledge in confronting challenges in school practicum.

It is interesting that pedagogical knowledge from university courses is not a significant predictor on practicality of this category of educational knowledge. As discussed, Taiwanese pre-service teachers should master skills of teaching because they need to demonstrate these skills in front of senior teachers for being employed by a school. 
Many university courses seriously emphasize pedagogical knowledge and often ask teacher education students to observe school teachers' instruction, and even try to practice teaching before enrolling in a field-based course. However, the analytic result reveals that pedagogical knowledge from university courses was perceived as impractical in confronting challenges in school practicum. A potential reason is that each pre-service teacher did not necessarily have sufficient opportunities to practice their skills of teaching in actual teaching situations but make a similar practice in front of their classmates in university classroom. An academic course about how to teach is often enrolled by more than 40 teacher education students, resulting in fewer opportunities to practice teaching for each pre-service teacher. On the other hand, teaching practice accounts for 40 percent of assessment of the field-based course. For superior achievement as well as master of teaching skills for being employed in future, pre-service teachers often discuss skills of teaching with their mentors and further modify their instructional strategies in the classrooms. Based on the above consequences, it seems to be reasonable that pedagogical knowledge acquired from the field-based courses can significantly predict practicality of this category of educational knowledge.

\section{Conclusions and Implication}

Teacher education courses, consisting of university courses and a field-based course, are able to equip pre-service teachers with educational knowledge to face educational practice. However, these courses do not guarantee that pre-service teachers can sufficiently confront the challenges in their school practicum through employing educational knowledge. This study aims to understand how the pre-service teachers rank their educational knowledge acquisition from both of the teacher education courses as well as the practicality of the knowledge in confronting challenges in school practicum and further determines which source of educational knowledge, acquired from the university courses and the field-based course, can predict the practicality of the educational knowledge.

This study concludes that disciplinary content knowledge was the top-ranked one among all of educational knowledge perceived by pre-service teachers in university courses, while this knowledge was perceived as the fifth-highest order educational knowledge in the field-based course as well as was perceived as the fourth-highest order on practicality of the knowledge in confronting field-based challenges. The finding implies that university courses in teacher education program do not fit to the needs of pre-service teachers in confronting the challenges in their school practicum. Except for disciplinary content knowledge, other categories of educational knowledge tended to maintain approximate rank-order.

Another conclusion indicates that all categories of educational knowledge from the field-based course, consisting of disciplinary content knowledge, school administrative knowledge, interpersonal relationship knowledge, consultation knowledge, self-reflection knowledge, and pedagogical knowledge, were significant predictors of practicality of the educational knowledge, while those acquired from university courses were not. The study result also identifies the value of the field-based course on teacher education programs

The present study demonstrates the importance of a field-based course in teacher education program. In Taiwan, a teacher education college has increasingly been shifted to a university with a teacher education institute. Initial teacher education program is simplified by academic courses. Simplified academic courses seem to hardly equip a teacher with various competences, resulting in pre-service teachers with impractical knowledge to confront potential challenges in school practicum. In contrast, a field-based course provides adequate environment to acquire practical knowledge to strengthen pre-service teachers' competences. As mentioned, a theory-practice relationship, connecting university courses and a field-based work, allows pre-service teachers to employ the skills and knowledge acquired at previous courses as well as to reflect on their actions through theoretical frameworks that can be interrogated and refined. Teacher educators in university should sufficiently collaborate with schools' teachers to construct the opportunities of combining theorizing knowledge and school practices. This study recommends that teacher educators in a university should build a course version of practical knowledge through integrating field-based experiences into teacher education courses.

This study has a limitation. Even though the Ministry of Education of Taiwan has established teacher education regulations that regulate teacher education institutes to implement teacher education programs, each university with teacher education institute can still perform a bit different of techniques for equipping pre-service teachers with competences, especially in delivery of teacher education courses. This study only sampled one university, Thus, it cannot be generalized to all Taiwanese teacher education students since the sample is convenient and the population is not well represented.

\section{References}

Baumert, J., \& Kunter, M. (2013). The COACTIV model of teachers' professional competence. Cognitive 
Activation in the Mathematics Classroom and Professional Competence of Teachers, 8, 25-48. http://dx.doi.org/10.1007/978-1-4614-5149-5_2

Celik, S. (2011). Characteristics and competencies for teacher educators: Addressing the need for improved professional standards in Turkey. Australian Journal of Teacher Education, 36(4), Article 2.

Cheng, M. M. H., Tang, S. Y. F., \& Cheng, A. Y. N. (2012). Practicalising theoretical knowledge in student teachers' professional learning in initial teacher education. Teaching and Teacher Education, 28(6), 781-790. http://dx.doi.org/10.1016/j.tate.2012.02.008

Cochran-Smith, M., \& Lytle, S. L. (1999). Relationships of knowledge and practice: Teaching learning in communities. Review of Research in Education, 24, 249-305. http://dx.doi.org/10.2307/1167272

Deed, C., Cox, P., \& Prain, V. (2011). Enablers and constraints in achieving integration in a teacher preparation program. Australian Journal of Teacher Education, 36(8), 1-92.

Eraut, M. (1994). Developing professional knowledge and competence. London, Washington, DC: Falmer Press.

Evelein, F., Korthagen, F., \& Brekelmans, M. (2008). Fulfillment of the basic psychological needs of student teachers during their first teaching experiences. Teaching and Teacher Education, 24, 1137-1148. http://dx.doi.org/10.1016/j.tate.2007.09.001

Feiman-Nemser, S. (1990). Teacher preparation: Structural and conceptual alternatives. In W. R. Houston, M. Huberman, \& J. Sikula (Eds.), Handbook of research in teacher education (pp. 212-233). New York: Macmillan.

Grootenboer, P. (2005/2006). The impact of the school-based practicum on pre-service teachers' affective development in mathematics. Mathematics Teacher Education and Development, 7, 18-32.

Joram, E. (2007). Clashing epistemologies: Aspiring teachers', practicing teachers', and professors' beliefs about knowledge and research in education. Teaching and Teacher Education, 23(2), 123-135. http://dx.doi.org/10.1016/j.tate.2006.04.032

LaBoskey, V. K. (2010). Teacher education and models of teacher reflection. In P. Peterson, E. Baker, \& B. McGaw (Eds.), International Encyclopedia of Education. Vol. 7 (3rd ed., pp. 629-634). Oxford, United Kingdom: Elsevier Limited. http://dx.doi.org/10.1016/B978-0-08-044894-7.00669-2

Maynard, T. (2007). The student teacher and the school community of practice: A consideration of "learning as participation". Cambridge Journal of Education, 31(1), 39-52. http://dx.doi.org/10.1080/03057640123915

Ministry of Education. (2011, January 4). Teacher education law enforcement rules. Retrieved January 18, 2013, from http://edu.law.moe.gov.tw/LawContent.aspx?id=FL008776

Ministry of Education. (2013, June 17). Implementation directions for pre-service teacher training courses. Retrieved June 18, 2013, from http://gazette.nat.gov.tw/EG_FileManager/eguploadpub/eg019111/ch05/type2/gov40/num15/Eg.htm

Montecinos, C., Walker, H., Rittershaussen, S., Nunez, C., Contreras, I., \& Solis, M. (2011). Defining content for field-based coursework: Contrasting the perspectives of secondary preservice teachers and their teacher preparation curricula. Teaching and Teacher Education, 27(2), 278-288. http://dx.doi.org/10.1016/j.tate.2010.09.001

Murray, F. B. (2010). Teacher education and the educational foundations knowledge base. In E. Baker, B. McGaw, \& P. Peterson (Eds.), International Encyclopedia of Education (3rd ed., pp. 662-668). Elsevier Science Ltd, Kidlington, UK. http://dx.doi.org/10.1016/B978-0-08-044894-7.00641-2

Tseng, K-H., Hou, S-C., Hsu, W-H., \& Chen, C-Y. (2006, July). Using knowledge acquisition platform in instruction to improve teachers' knowledge. Proceedings of the 10th WSEAS International Conference on COMPUTERS (pp. 289-294). Vouliagmeni, Athens, Greece, July 13-15, 2006.

\section{Copyrights}

Copyright for this article is retained by the author(s), with first publication rights granted to the journal.

This is an open-access article distributed under the terms and conditions of the Creative Commons Attribution license (http://creativecommons.org/licenses/by/3.0/). 